\title{
LA TENTATIVA INIDONEA O DELITO IMPOSIBLE
}

\author{
GIL NÚÑEZ, Juan Antonio ${ }^{111}$ \\ SUMARIO: 1. Introducción. - 2. Elementos del delito imposible. - 3. \\ Jurisprudencia.
}

\section{Introducción}

Dentro de las conductas humanas se encuentra el delito, el mismo que se encuentra dividido en distintas fases que contiene el Iter Criminis. Podríamos mencionar que inicialmente se encuentra un punto de inicio, ideación y actos preparatorios al evento a realizarse y finalmente un resultado que incurra en un determinado tipo. Sin embargo, en el proceso intermedio existen circunstancias que interrumpen la acción que se plantea

${ }^{111}$ Alumno de la Facultad de Derecho de la URP, miembro del Centro de Investigación. 
realizar y que aparecen por causas accidentales, voluntarias o naturales. Es así como el “fracaso" del acto y la no consumación se traducen a la denominada tentativa.

La tentativa es penada en el Perú con atenuaciones a la pena descrita en caso de haberse consumado el delito, por lo general las penas se reducen debido a que no se daño ningún bien jurídico. Sin embargo, es con el código penal de 1991 que se incorpora en el Derecho peruano la figura de la tentativa idónea o delito imposible basados en el principio de lesividad. Este principio nos indica que la tentativa idónea no es susceptible a ser sancionada debido a que no existe un bien jurídico dañado.

En la figura de la tentativa hay que tener en consideración que debe existir -en el Perú- el dolo, pues es el conocimiento y la voluntad de realizar una acción que posiblemente afectara o pusiera en evidente riesgo un bien jurídico el hecho sancionable.

Es con el anteproyecto del código penal de la comisión revisora de la ley 27837 que se modifican algunos términos del artículo 17 del código penal y se incluye el vocablo "inidoneo" el mismo que significa Ineficacia. Esta modificación es importante debido al significado lingüístico que incorpora, pues el termino "idóneo" según La Rousse significa: "suficiencia o aptitud para alguna cosa"112

"Estamos frente a una tentativa inidonea o delito imposible cuando la ejecución delictiva dirigida por el autor no llega a consumarse por razones fácticas o jurídicas. Los límites de la tentativa inidonea son precisados en el articulo 17 del Código Penal y ésta se presenta cuando la consumación del delito resulta imposible debido a la ineficacia del medio empleado o absoluta impropiedad del objeto."113

Existen algunas doctrinas que sostienen el tema del delito imposible, las más importantes son la doctrina subjetivista y la objetivista. La doctrina objetivista sostiene que no es necesario incorporar punibilidad a los actos de tentativa idónea, debido a que no se pone en peligro el interés jurídico protegido. "la manifestación de voluntad no basta para dar vida al delito, del que es requisito esencial el daño, ya sea inmediato o directo" $" 114$ queda claro que para los objetivista el principio de lesividad exige que mientras no exista afectación no se puede imputar cargo alguno al sujeto. Es aquí que juega la figura del "peligro" pues depende de si existe o no peligro de afectación la tentativa es pausible de punibilidad. Para GAROFALO estos criterios están basados en la peligrosidad del sujeto y sin tener en cuenta el elemento objetivo. ${ }^{115}$

112 LA ROUSSE, 2002. Diccionario Enciclopédico. Bogota, PP.539

${ }^{113}$ VILLAVICENCIO, Derecho Penal. Parte General p. 450

${ }^{114}$ CAVALLERO, El delito imposible p. 93

${ }^{115}$ EZAINE, El “ITER CRIMINIS” p. 117 
Dos figuras más se comprometen con el delito imposible y son las de la tentativa absolutamente idónea y la de la tentativa relativamente idónea, la primera de ellas es inimputable debido a que el medio o el objeto no era idóneo para la realización del tipo penal. Mientras que la segunda, son las condiciones externas al sujeto las que le impiden realizar el injusto. ${ }^{116}$ En esta ocasión es fácil apreciar que a pesar que en ambas tentativas se encuentra la intención -dolo- de realizar el acto en la primera de ellas es imposible la ejecución debido a que existió un "error" en la planificación o en el conocimiento previo del agente activo, pero en el segundo caso, vemos que los medios eran idóneos para realizar el acto, pero es un agente externo quien impide la realización del hecho. Situación que deja un espacio abierto a la posibilidad que el sujeto pueda intentar perpetrar el acto en una nueva oportunidad donde no este presente o sea inexistente el agente externo, situación que coloca al Delito imposible en una posibilidad a futuro existiendo un riego evidente a la afectación de un bien jurídico si el sujeto no fuera sancionado. Es siempre importante distinguir la distinción entre las especies de inidoneidad absoluta e inidoneidad relativa. ${ }^{117}$

Situación distinta a la que se puede apreciar en la tesis subjetivista que sostiene que aun cuando se dieran las condiciones de la impropiedad del objeto y la inidoneidad del medio empleado es suficiente la voluntad del sujeto para que la conducta sea punible, basado en que de algún modo -abstracto- la conducta del sujeto que intenta cometer un delito pretende poner en riego un bien jurídico considerando a esta conducta antijurídica.

Debe señalarse que la tentativa en sí, es un delito. Pero la inidoneidad de la tentativa debe referirse al resultado más no a la conducta. ${ }^{118}$ Entendemos a la inidoneidad desde dos perspectivas para calificar al delito imposible; Impropiedad del objeto y la ineficacia del medio. Muy controversialmente se incluye en algunas legislaciones la idoneidad del sujeto.

Ahora, es imprescindible identificar que toda conducta aparentemente inidonea no siempre lo es, pues es verificable que -como expresa Núñez Barbero- Una conducta inidonea en un determinado caso (Suministrar azúcar en un vaso de agua y dárselo a una persona) no es un medio idóneo para cometer homicidio, pero podría ser idóneo en otro

${ }^{116}$ MITTERMAIER, Der Versuch des Verbrechen

117 Según NOVOA MONREAL "Hay inidoneidad absoluta cuando los medios empleados o el objeto sobre el cual se emplean esos medios, hacen imposible, por ley natural, obtener el hecho delictuoso intentado; por ejemplo, en los casos de envenenamiento con sal común y del atentado contra un cadáver..."

"Hay inidoneidad relativa cuando los medios o el objeto tienen por si mismos la aptitud para conseguir el resultado, pero este no llega a producirse en el caso concreto por circunstancias particulares que en él hacen inoperante el intento; por ejemplo, disparar contra la persona que se encuentra a distancia a la cual no alcanza el proyectil, o disparar contra el lecho de la victima, creyendo que ella está acostada con él, cuando en realidad acaba de abandonarlo.”

118 SOLA RECHE, La llamada Tentativa, p. 12 
caso (Si la victima fuese diabético). Por lo que es ampliamente entendible que no basta analizar el la propiedad del objeto o la idoneidad del medio, sino que ello debe ser analizado conjuntamente con el caso concreto, con el contexto y con la intención de los involucrados. ${ }^{119}$

Sin embargo para el Italiano VICENZO MANZINI el tema no se agota en la posición de Barbero, sino que considera que solo la Inidoneidad hace impune la tentativa ya que la insuficiencia -de los medios u objetos- no equivale al de idoneidad relativa. ${ }^{120}$. Sin embargo es claro que la tentativa en cualquiera de sus formas constituye un peligro evidente como resultado de la voluntad humana, lo que nos llevaría a la discusión si realmente debería quedar impune un acto de tentativa que cumpla con los requisitos de la Tentativa inidonea.

“... el juicio de idoneidad debe suponer la constatación y valoración de un acto, o de una serie de actos, que, en unión de todas aquellas circunstancias en las cuales se desenvuelven, sean capaces, aptos, eficaces para la productividad del resultado consumativo". ${ }^{121}$

\section{Elementos del delito imposible}

La Inexistencia del objeto es uno de los elementos para reconocer un delito imposible, pues es la falta, carencia o inexistencia de un objeto material sobre el cual cometer el acto delictivo y aun cuando este existiera debe poseer las condiciones o características propias en cuyo caso de ser afectadas se encuentres previamente señaladas en un tipo penal, para poder actuar bajo el principio de legalidad.

El "medio" es otro de los elementos circundantes en cuanto a la tentativa inidonea, pues la ineficacia del medio es también pausible de inpunibilidad. El medio puede ser afectado absoluta o relativamente dependiendo del caso concreto y de manera Natural o por "error" en el sujeto activo.

Aquí concurre también el tema del error; pues si bien una tentativa es producto de una acción premeditada, donde los objetos son identificados y los medios son considerados óptimos por parte del sujeto activo par la realización del delito, éste puede incurrir en error y puede de manera conciente o inconciente errar en la ultimación de los elementos necesarios para la perpetración del ilícito. En este caso es necesario recordar que la intención es evidente y siguiendo la lógica objetivista al existir un error en la utilización o empleo idóneo del medio u objeto en cuestión, no hay pena. Sin embargo no

${ }^{119}$ NUÑEZ BARBERO, El delito imposible

${ }^{120}$ MANZINI, Trattato Di Diritto Penale Italiano

${ }^{121}$ NUÑEZ BARBERO, El delito imposible p. 113 
existe una prevención general que permita que este acto no pueda ser cometido a posterioridad. ${ }^{122}$

Cabe mencionar una diferencia sustancial par evitar confusiones con el delito imposible, y es con respecto al delito putativo, es una figura atípica pues no se encuentra prevista en la normatividad penal. Es cuando en el ánimo del agente media la creencia que su acto es un delito consumado, teniendo en consideración que en ocasiones no se configura ningún delito. ${ }^{123}$

Es de estimar, que el delito imposible no era punible, pero podía ser un inequívoco síntoma de peligrosidad personal del autor, declaro el artículo $9^{\circ}$ de la Ley de Vagos y Maleantes del 4 de agosto de 1933 en España. "Los hechos que no constituyan delito por su inidoneidad del medio o inexistencia del objeto" podrán ser "susceptibles de examen y consideración a los efectos de declarar el estado peligroso y la consiguiente aplicación de las medidas de seguridad"124

\section{Jurisprudencia}

Se presentan jurisprudencia por tres materias; por la falta de tipo, por la inidoneidad del medio o del comportamiento y por Inidoneidad del objeto.

\section{Falta de tipo}

"No configura delito imposible punible, el hecho de golpear con un garrote y con propósito homicida la cabeza de un cadáver, porque la peligrosidad del autor del hecho es el fundamento del delito imposible, pero circunscripto a la tipicidad siendo indispensable la existencia de un bien jurídico protegido, contra el que se atenta en forma inidonea" (Cám. $2^{a}$ Penal Tucumán, 12/8/68, “monteros, Mamerto M. y otro”, en “J.A.”, 1968-vi562)

"No incurre en delito de agresión del art. 104, in fine, del CP., ni en tentativa de delito imposible, el sujeto que apunta a otro con un arma de fuego que sabe descargada" (Cám. Apel. $1^{\text {a }}$ Penal San Isidro, 28/8/79, “serrano, Hector J. N.”, en “L.L.”, 141-338)

\section{Inidoneidad del medio o del comportamiento}

${ }^{122}$ Para Ezaine ““'Para resolver esta problemática la ley penal castiga el delito imposible, atendiendo al peligro que representa el delincuente, distinguiéndose varios sistemas: castigando el caso de medios inidoneos y dejando impune el de la inexistencia del objeto; castigando el caso de tentativa con medios no absolutamente inidoneos; rebajando la pena; proclamando la impunidad con excepciones; declarando la impunidad cuando dimana peligro...”

${ }^{123}$ EZAINE, El “ITER CRIMINIS” p. 125

${ }^{124}$ RODRIGUEZ, Delito imposible y tentativa del delito en el Código Penal español 
“...existe tentativa de delito imposible, cuando mediante la adulteración burda de una libreta de ahorro se intento estafar a los funcionarios de la Caja Nacional de Ahorro Postal, pues si bien el medio empleado es idóneo teóricamente para defraudar, dicha idoneidad desaparece, debiendo equipararse la situación con la propia de una inidoneidad absoluta por imposibilidad de engaño a terceros acerca del verdadero estado del documento". (Cám. Nac. Fer., Sala Crim y Correc., 24/2/59, "landriel de Ybasca, Celestina”, del voto del Dr. Ramos Mejía, en “J.A.”, 1959-IV-51)

"Si la tentativa de viajar con un boleto marcado estaba destinada por anticipación al fracaso, debe apreciársela como una hipótesis de un delito imposible. (Brizuela, Carlos A.” en “rep. L.L.”, XXXII-459)

"No se esta en presencia de un caso de desistimiento voluntario de la tentativa, sino frente a un caso de tentativa de delito imposible por falta de idoneidad del medio utilizado para cometer el delito, el procesado desistió del intento de apoderarse del automóvil por no ceder a acceder al vehiculo con la llave que llevaba" (Cám. Nac. Crim y Correc., Sala IV, 7/10/75, “Elizari, Carlos”, en “J.A.”, 1976-11-537).

\section{Inidoneidad del objeto}

"En la tentativa del delito imposible, la imposibilidad debe referirse en concreto a la acción que el agente se propuso a realizar y forma y circunstancias que contaban en sus designios... así existe esta figura si el procesado intentó apoderarse de una victrola que supuso en el domicilio de una persona ausente, lo que no pudo llevar a cabo porque el dueño había trasladado el objeto a otro lugar” (Cám. Fed. Bahía Blanca, 23/7/41, "Zárate Saturnino”, en "L.L.”, 27-740).

"Hay delito imposible si al entrar el procesado al camión de donde debía sustraer las mercancías, éstas no habían sido cargadas aún” (S.C. Tucumán, 22/7/47 en “J.A.”, 1948-II-549

En la jurisprudencia anterior es visible una diversidad de casos donde la aplicación de la tentativa inidonea en el desarrollo de un caso concreto exime de pena al sujeto activo -aun cuando este se encuentre imbuido del dolo- sin embargo, si bien en el Perú se considera inimputable a los casos bajo esta modalidad en estricto cumplimiento del principio de lesividad, en el Código Penal Argentino en su articulo $44^{\circ}$ señala "Si el delito fuere imposible, la pena se disminuirá en la mitad y podrá reducírsela al mínimo legal o eximirse de ella, según el grado de peligrosidad revelado por el delincuente”.

Es observable que con esta pena, no se busca someter al imputado a una sanción draconiana por un hecho que no se consumó, sino por el contrario, funcionar como prevención así como en algunas legislaciones adoptar medidas de seguridad para evitar futuras comisiones. 


\section{BIBLIOGRAFIA}

- CAVALLERO Ricardo Juan, La tentativa inidonea en el Derecho Penal argentino. Editorial Universitaria. 1983. Buenos Aires

- EZAINE CHAVEZ Amado, El “Iter Criminis”. Primera edición. Editorial "bolivariana”. 1969 Chiclayo-Perú

- LA ROUSSE, 2002. Diccionario Enciclopédico. Bogota-Colombia

- MANZINI Vicenzo, Trattato Di Diritto Penale Italiano

- MITTERMAIER, Der Versuch des Verbrechen

- NOVOA MONREAL Eduardo, El proceso de generación del delito. Tentativa y Delito Imposible. Publicaciones de la Facultad de Ciencias Jurídicas y Sociales de la Universidad de Concepción. 1963, Chile.

- NUÑEZ BARBERO Ruperto, El delito imposible, Editorial “Diario-Día” Tomo V, Núm. 1, 1936 Salamanca-España

- RODRIGUEZ MOURULLO Gonzalo, Delito imposible y tentativa de delito en el código penal español. Madrid-España

- SOLA RECHE, La llamada Tentativa

- VILLAVICENCIO TERREROS Felipe, Derecho Penal. Parte General. Ed. Grijley. 2006. Lima 